\title{
Nanotechnology in Repair and Protection of Structures State-of-the-Art
}

Sherief Abulmagd ${ }^{1}$ and Zeinab A. Etman ${ }^{2 *}$

${ }^{1}$ Department of Civil Engineering, Helwan University, Egypt

${ }^{2}$ Department of Civil Engineering, Menoufia University, Egypt

\begin{abstract}
There can be many causes of deterioration in concrete structures. Concrete repaired is a specialist activity requiring fully trained and competent consultants and companies at all stages of the process. Often simple "patch and paint" strategies have been employed as short term cosmetic repairs which have failed to address the root cause of the problem and have, as a result, often failed to meet structure owners expectations. Nanotechnology provides insight into the use of nanomaterials in the following areas:
\end{abstract}

Protection against ingress- moisture control- concrete restoratio - structural strengthening- physical resistance to chemicals- preserving or restoring passivity- increasing resistivity- cathodic control- cathodic protection control of anodic areas.

This paper is state of the art for using nanotechnology in repair and protection of concrete structures. It is hoped that this paper will help researchers to be aware of the most recent progress in this important field.

Keywords: Nanomaterial; Nanotechnology; Repair; Protection; Corrosion; Self-healing

\section{Introduction}

\section{Highlights}

Nanotechnology is an extension of sciences and technologies. Nanotechnology has amazed benefits in different applications in the construction industry. Nanotechnology has positive effect on the area of design, repair, protection, construction, maintenance. It is recommended to carefully studying the effect of nonmaterial on the heath of humans and the environment.

\section{Literature Review}

\section{Repair and refurbishment: An overview}

Repair and refurbishment of structures consumes a quarter of the annual budget of the construction industry. As the infrastructures and structures age, budget and resource limitation on new construction becomes striker. Repair and refurbishment consume a lot of budget, resources and effort. On the other hand, the repair of deteriorating concrete structures is a vital part of the wider picture of the construction sector.

\section{Nanotechnology for building materials}

Introduction to nanotechnology: Nanotechnology is not a new science and it is not a new technology. It is an extension of sciences and technologies. Nanotechnology is the technical understanding of the physical world on a very, very, very small scale. The technology enables us to develop materials with modifying properties or it used to manufacture a totally new material [1-3]. It is the invention of materials by checking of matter at many levels: atoms, molecules, and submolecular structures. It is also defined as the application of fine particles of material to make new large scale of material. Nanotechnology needs sophisticated techniques to enhance the manner of materials by creating particles of 1 to 100 nanometers (nm) [4,5]. Some assessments predict that outputs and services regarding to nanotechnology could reach 1,000,000 million euro/year after 2015 [6]. Gogotsi defines the nanotechnology as the technique used for improving the material behavior and for designing and producing very fine powders, liquids or solids with particle size between 1 and $100 \mathrm{~nm}$. Nanotechnology is the engineering of practical systems at the molecular scale [7]. If the earth's diameter is one meter then $\mathrm{nm}$ is the diameter of a football.

What can be generating?: Nanotechnology can generate products with many marvelous characteristics that can improve the current repair and protection materials: lighter and stronger composites, low maintenance coating, better cementatious materials, poor heat transfer rate, fire retardant and insulation. Because the size of the particles is a significant factor, the materials properties differ at the nano-scale from that at larger scale. Physical phenomena begin to happen below that: gravity becomes inconsequential, electrostatic force and quantum effect start to prevail. At the same time, the properties of atoms on the surface augment proportional to those inside creating the so-called "Nanoeffect". All these nano-properties actually affect the materials behavior at macro-scale and from this point; the power of nanotechnology is emphasized. If the elements are properly manipulated at the nano-scale, the macro-properties are affected and new materials and processes can be developed. Some important nano-materials with potential use in repair and protection of concrete structure are given here.

Nanotechnology for concrete: Ganesh [8] reported some application of concrete structures and a lot of the developments due to the nanotechnology. To beat on segregation phenomena, nanosilica was used for self-compacting concrete and to control the damage of the $\mathrm{C}-\mathrm{S}-\mathrm{H}$ (calcium-silicate-hydrate) reaction of concrete and improves its stated durability. $\mathrm{Li}$ [9] reported that the compressive strength for concrete increases by using nano-SiO2 at early age. Also; enhance pore size distribution can occur by filling the pores between cement particles with nano-scale. Ganesh and Saurav $(2012)[8,10]$ were able to improve the overall cluster packing in concrete matrix leading to increase the compressive strengths. Using fiber sheet containing nano-silica particles and hardeners permeate and close tiny cracks on the concrete surface. In case of strengthening applications, a strong bond between the surface of the concrete and the fiber reinforcement was recorded.

Nanotechnogy for coatings and isolation: Nanocaotings are considered of the advantages of nanotechnology. The compositions of

*Corresponding author: Zeinab A. Etman, Department of Civil Engineering, Menoufia University, Egypt, Tel: +20482222170; E-mail: dr_zeinab_2006@yahoo.com

Received February 12, 2018; Accepted April 04, 2018; Published April 06 , 2018

Citation: Abulmagd S, Etman ZA (2018) Nanotechnology in Repair and Protection of Structures State-of-the-Art. J Civil Environ Eng 8: 306. doi: 10.4172/2165784X.1000306

Copyright: $\odot 2018$ Abulmagd S, et al. This is an open-access article distributed under the terms of the Creative Commons Attribution License, which permits unrestricted use, distribution, and reproduction in any medium, provided the original author and source are credited. 
nanocoatings are nanoparticles which are dispersed in a liquid medium and achieve a very high surface area to the volume ratio. Due to these nanoparticles [3], corrosion resistance, antimicrobial properties improve because of improved properties (hardness, wear, good adhesion, and extreme flexibility. As a standard the recycling of coat of paint should contain minimum $20 \%$ recycled content and recycle of vessels also solve the matter of disposal, emission from residues. All these is possible with the nanocoatings. In India this coating had been widely used in the structures of New Delhi Common wealth Games 2010 [11]. The application of organic coatings on concrete is the most popular way for the protection of both the concrete and the steel reinforcement against weathering and corrosion performing. Coatings prevent the access carbon dioxide and chlorides, from the meduim into concrete. Nanotechnology is being used to paints and insulating material. Generate by the addition of nano-sized cells, pores and particles, giving very limited paths for thermal conduction are presently available. These coatings are hydrophobic and repel water from the metal pipe and can also protect metal from salt water aggression. Silica aero gel particles with nano-sized pore in combination with reinforcing fibers in paints and coatings are used because of aesthetics reasons and protection and are also used for insulating properties. Patel and Mann studied the effect of self-properties of $\mathrm{TiO}_{2}$ as a Nano material $[12,13]$.

For example, the evaluation of paints and finishing materials that are self-cleaning, discoloration resistant, ant-graffiti protected, high scratch resistant and wear resistant is extremely important for façade and interior applications. Self-cleaning Hydrotect tile, window glass, and water-based paint have been developed based on photocatalyst technology. The self-cleaning effect related to decomposition of organic pollutants and gases is achieved [14,15] (Figure 1). An application for residential house built with concrete blocks manufactured with the silicone mixture has retained its original condition after several years (Figures 2 and 3). These concrete blocks used for building the Retaining containing illustrated a clean finish for years (Figure 4). Pavers containing the silicone mixture around salt water swimming pools retained their original appearance in a salty water environment
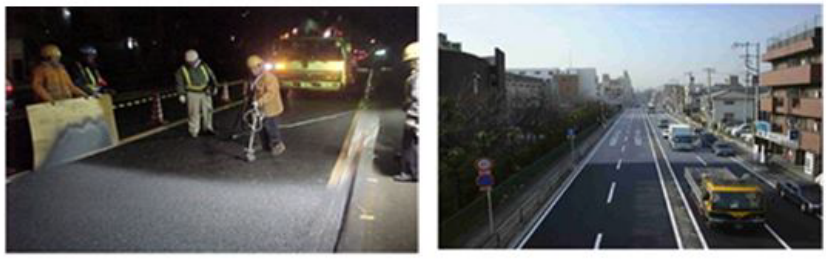

Figure 1: $\mathrm{TiO}_{2}$ coating on roads for pollution reduction.

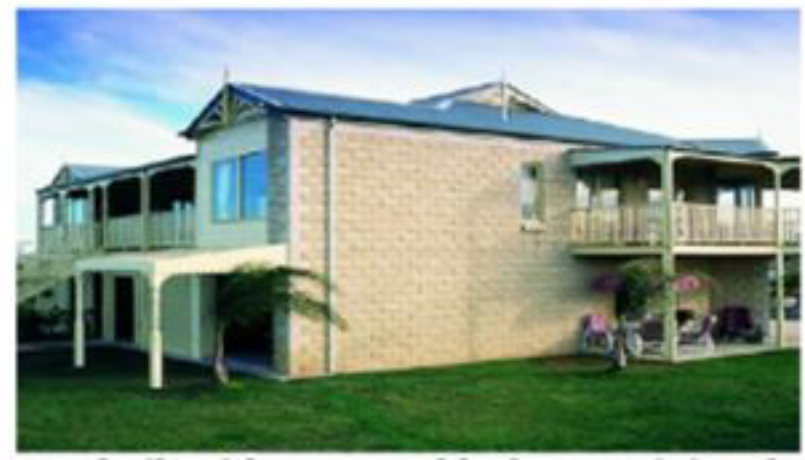

Figure 2: House built with concrete blocks with silicon mixture.

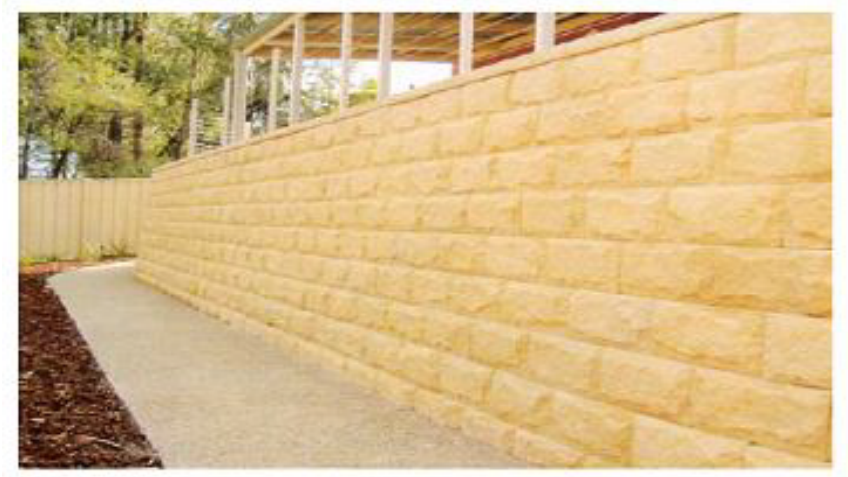

Figure 3: A retaining wall built with concrete blocks with silicon mixture.
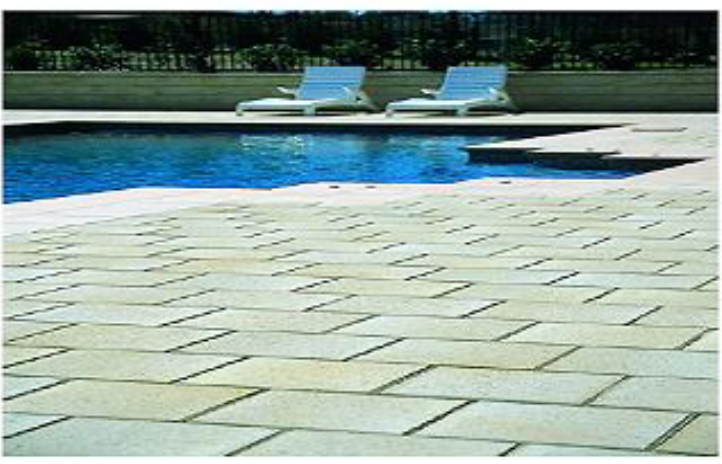

Figure 4: Concrete paving with the silicon admixtures around a water pool.

for several years (Figure 4). Addition of the silicone watered repellent mixture into pressed concrete imparts significant water repellency. Efflorescence phenomena of the concrete were effectively controlled. in Australia, the concrete block and paver industries have been proven a great remarkable as unique application of the silicon mixture for the past 15 years.

Nanotechnology is used as materials for fire safety: In the traditional methods to providing fire resistance to structural elements depend on either increasing thicknesses of non-structural materials, which is wasteful of resources, or using costly intumescent coatings. Nanotechnology was applied to resist the high temperature. This is achieved by the mixing of carbon nanotubes (CNT's) with the cementatious material to fabricate fiber composites that can inherit some of the wonderful properties of the nanotubes as strength. To manufacture protective clothing materials for retarding the flame the CNTs can be used. Where it is improving the structure for fire protection by involving the application of inorganic layers as a surface protection system on combustible materials like wood and polymeric materials as a one of the used mechanisms [16].

\section{Functional nanosensors}

Smart nanosensor materials: Smart or intelligent structures are those that can monitor their own condition, detect impending failure, control damage and adapt to changing environments. Potential applications of smart materials or systems include smart aggregates in concrete; design of smart surfaces embedded with fiber optic sensors to detect structural failures; bridges with sensors or actuating elements to counter violent vibrations; remote controlled flying Micro-ElectroMechanical Systems (MEMS) for surveying and rescue missions, stealth submarine vehicles with swimming muscles made of special polymers 
(Figures 5 and 6). Sensors used in smart structures or materials. Sensors used in smart structures or materials. These sensors contain optical fibers, corrosion sensors, and other environmental sensors and sensing chips. Examples of smart structures and materials are listed by Chong, Ken. Small dosages of carbon nanotubes that increase the electrical conductivity of polymeric composites and can then be used to detect cracks in the composite, showing as a reduced conductivity at the cracked section. The Confederation Bridge in Canada has a length of $12.9 \mathrm{~km}$, making it the longest bridge over iced water in the world. Sensors were built into advanced composite materials to measure corrosion risk. This way of using nanotechnology has resulted in fewer repair work and less road closures. Research is looking at the possibility for embedding nanosensors in road pavements to monitor the processes that contribute to deterioration and cracking [17-20]. Nanotechnology is developed already include self-cleaning materials, such as glasses and paints. An important achievement behind this is the use of the photocatalysis mechanism. Using nano-scale titanium dioxide is primarily achieving this phenomenon. One of the applications is treatment the concrete in church in Rome to produce white, clean surfaces. Different surface can be used this technology such as concrete, metal, ceramics, polymers and textiles, resulting in products such as: Self-cleaning concrete surfaces, Self-cleaning toilets, bathrooms, kitchens, hospitals etc. Self-cleaning paints, Self-cleaning window frames, sun screens, tents etc. [16,21].

Conductive concrete: There was great interest in making the top surface of concrete conductive, allowing the surface to be warmed slightly to prevent freezing in winter. This would have enormous cost savings from the point of spreading of natural rock salt onto ways and bridges, and the point of reduced deterioration of bridges and

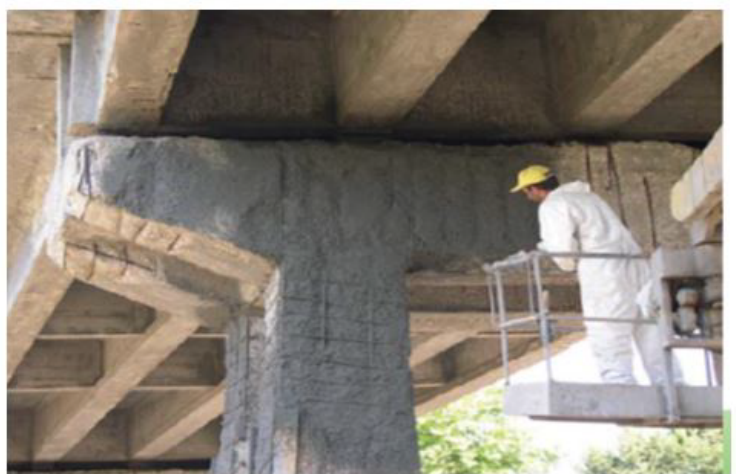

Figure 5: Repair of concrete element of all bridges, marine and other civil structures.

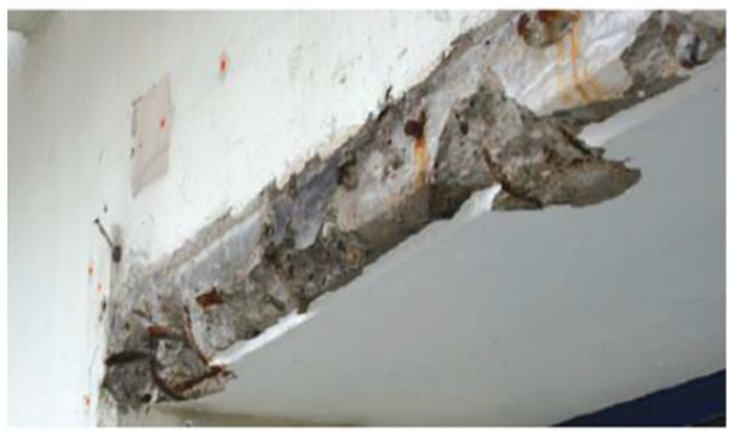

Figure 6: Reprofiling of old reinforced concrete structure and repair of concrete beams of the balconies of office building in Brussels.
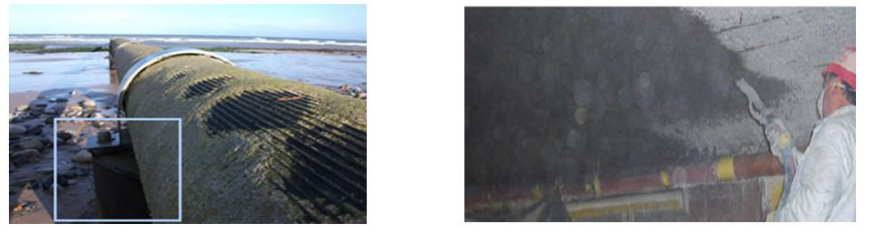

Figure 7: Repair of below ground construction as tunnel and pipes in aggressive ground conditions.
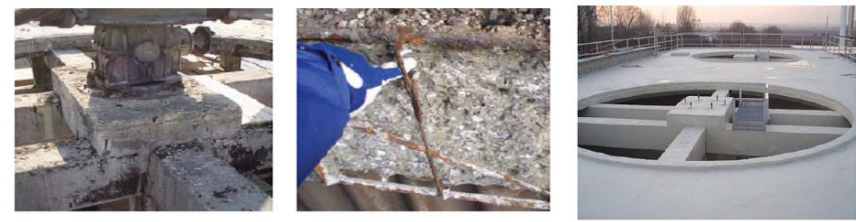

Figure 8: Cooling tower: Structural concrete repair and reprofiling.

abutments regularly doused in salt and reduced contamination of water courses. In the late 1990s, research was progressing on the expansion of conductive concrete and cement-based overlays. Conductive concrete was used on the Roca Bridge outside Lincoln, Nebraska, USA. More recently, the use of carbon fibers were discovered and now nano-tubes are being examined, as they offer very high surface area. Less than $1 \%$ of carbon fibers were used in the concrete by volume have big effect in improving the electrical concrete conductivity. Conductive concrete shows interesting and different properties with regard to ordinary concrete as follow: Ability to monitor itself for cracks because of the fibers' ability to conduct electricity. Conductive concrete for roads able to monitor and weigh passing traffic ability to heat a road, a bridge, or a runway through electric current leading to snow and ice-free surfaces. Ability to control heating and lighting systems [21].

Water content: Half of the wood products now used in construction are engineered wood composites. Nanotechnology will result in a unique next generation have hyper-performance and superior such as the wood (Figures 7 and 8). This type of wood bears the serviceability due to severe environments. Nanotechnology will result in a unique next generation have hyper-performance and superior such as the wood. This type of wood bears the serviceability due to severe environments. The intelligent wood and bio-composite products were also developed by nanotechnology by achieving the array of wood with nanosensors built in. self-sterilizing surface, internal self-repair and electronic devices were a new opportunity to use for building functionality onto lignocellulosic surfaces at the nanoscale. Due to the high strength in addition to the potential economic advantages of nanofibrillar will display the chance to make lighter weight, stronger materials with major durability [22].

\section{Concrete Repair-Existing Situation}

\section{Nanocrete: A new generation of concrete repair products}

Reducing cracking tendency: Because of the hydration process, reducing cracking tendency of cement shrinkage happens. When the stress of the shrinkage becomes more than the natural tensile strength of a mortar the cracks will happen. Nanotechnology keeps the balance between these two forces to block cracking (Figures 9 and 10).

Over 50 years of technology innovative in the field of cement: Nanotechnology has applications in virtually every domain including medicine, engineering, manufacturing, electronics and material and computer sciences. But compared to other areas, application in construction engineering and the built environment is still a very small 
scientific circle [23]. Feynman has passed the Nobile prize because he opens the way for the innovations related to nanotechnology Over 50 years [1] (Figures 11 and 12).
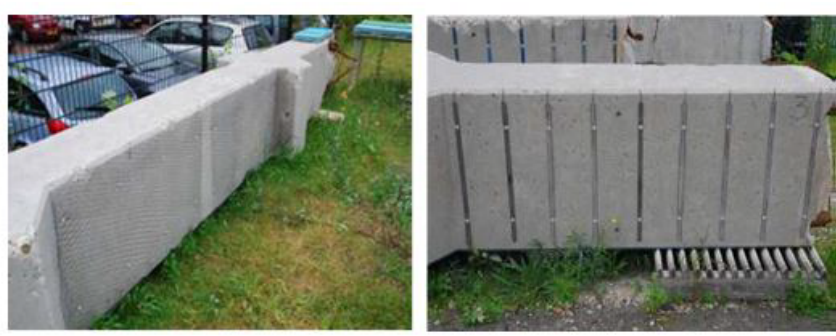

Figure 9: Nano-materials for self-healing of certain interfaces within corrosion and cathodic protection in reinforced concrete.
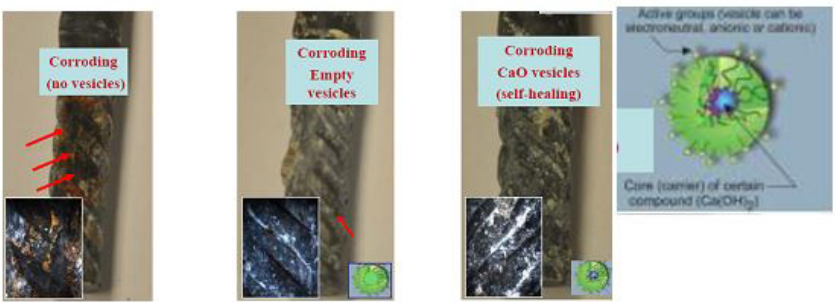

Figure 10: Increased corrosion resistance with $\mathrm{CaO}$ containing vesicles after 240 days $(5 \% \mathrm{NaCl})$ - self-healing mechanism.

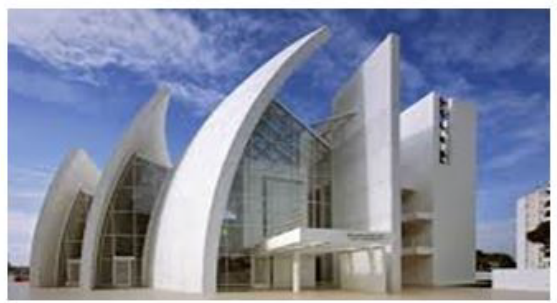

Figure 11: Building made by using self-cleaning concrete (Church "Dives in Misericordia", Rome, Italy).
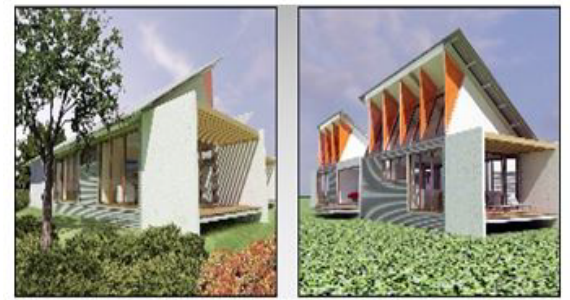

Figure 12: Nano house, Australia.

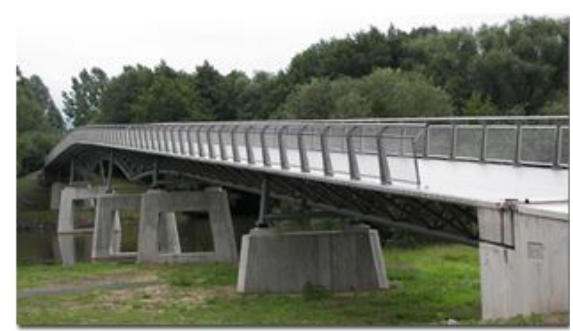

Figure 13: The Gartnerplatz brucke, across Kassel river in Germany.

\section{Improving repair mortars with nanotechnology}

Understand the process of cement hydration, developed over the past 50 years, helps us to improve the microstructure of the nanostructures formed in the cement paste as it hardens. This reduces micro-defects result during the hardened cement. Also improves the bond between the cement matrix and the aggregate. This improves technical performance e.g. density, tensile and compressive strength, and freeze thaw resistance (Figure 13).

Types of nano-mortars: A "nanostructured material" can be defined as a traditional material such as steel, cement, glass or polymers - admixed in mass or surface with nano-materials (nano-composite) or modified in its chemical composition beside to physical structure through observation, testing and characterization of the properties at nano engineering. The main Nano particles utilized in construction materials are: Nano Silica $\left(\mathrm{sio}_{2}\right)$, Titanium dioxide $\left(\mathrm{Tio}_{2}\right)$, and Carbon nanotube (CNT), Nano gold [24].

Nano Silica ( $\left.\mathrm{Sio}_{2}\right)$ : The main Nano particles utilized in construction materials are: Nano Silica $\left(\mathrm{SiO}_{2}\right)$, Titanium dioxide $\left(\mathrm{Tio}_{2}\right)$, and Carbon nanotube (CNT), Nano gold [24]. Nano Silica $\left(\mathrm{Sio}_{2}\right)$ : the mixture of Nano silica with concrete improves the mechanical properties and reaction of concrete. Also, it is controlling the degradation of C-S-H leads to prevent of water penetration causing major durability, and strength of concrete.

Titanium dioxide $\left(\mathrm{Tio}_{2}\right)$ : have a white color and could be an excellent reflective coating and sun block. When Tio2 is mixing with concrete causes the pollution to be broken down and washed off by rainwater

Carbon nanotubes (CNT): CNT are cylindrical with a diameter of 1 nanometer are theoretically 100 times as strong as steel but have only tested to be 8 times stronger. CNT could be mixed with the concrete which improves the mechanical properties.

Up till now more researching still on the nanoparticles has been with nano- $\mathrm{SiO}_{2}$ and nano- $\mathrm{TiO}_{2}$. A few works on nanoparticles incorporating nano-iron (nano- $\mathrm{Fe}_{2} \mathrm{O}_{3}$ ), nano-alumina (nano- $\mathrm{Al}_{2} \mathrm{O}_{3}$ ), and nanoclay particles. Additionally, a limited number of investigations is dealing with the manufacture of nanosized cement particles and the development of nanobinders [9,25-27]. Sobolev et al. [28] stated that the developments in nano-science and its great impact on the domain of construction materials. They cast mortar with nano- $\mathrm{SiO}_{2}$ synthesized to examine the mechanical properties by sol-gel method. An increasing in the compressive strength with improved nano-particles at early ages. It is noticed that loss gains in the compressive strength at later age. They proposed to add superplasticizer overcome this obstacle. The results demonstrated that increasing in the compressive strength by $15-20 \%$ at 90 days by using superplasticizer. Peng et al. [29] measured the ultimate strength for multi-walled carbon nanotubes. Carbon nanotube has excellent mechanical properties. This yield to be grown the number of applications from ballistic armour to Nano electronics. They reported that multi-walled carbon nanotubes with a mean fracture, which exceeds earlier observations by a factor of approximately three. They found agreement for the experimental results with quantum-mechanical estimates for nanotubes. To determine the number of fracture shells, they used the high-resolution imaging. Also the chirality of the outer shell was determined by the same method. Engineering ceramics has high stiffness, excellent thermo stability, and low density, but their brittleness blocks their use as structural materials. In summary, the alumina matrix of MWCNTs achieved a homogeneous distribution based on the precursor method for alumina and acid-treated MWCNTs. They introduced the chemically modified 
MWCNTs by enhanced frictional resistance through the mechanical interlock. This approach yield to increase in strength and toughness of MWCNT/alumina composites

\section{Advantage of nanotechnology in repair and protection of reinforced concrete}

\section{Self-Healing concrete}

Nanomaterial is the only allow to the small cracks to form. When the water is added; the cracks will repair themselves [30].

\section{Permeability and abrasion}

Concrete containing nano-particles have the abrasion resistance much larger than that of polypropylene fiber concrete. In addition to, the concrete containing nano- $\mathrm{TiO}_{2}$ has abrasion resistance better than that containing the same amount of nano- $\mathrm{SiO}_{2}$. Protect concrete from penetration of aggressive media, is one of the most important contributory factors to the concrete's durability. Ardalana et al. studied the effects of nano-SiO2 particles on concrete permeability. They used the technique of spraying nano-silicon and treatment in the water-diluted nano-SiO2 oxide. They resulted that, using nano$\mathrm{SiO} 2$ particles on concrete yield to increasing in the compression strength and the permeability where improvement of nanostructures of the concrete. nano-SiO2 particles participate in the completion of the hydration process, and development of a protective layer, and therefore the increase of bulk concrete panel durability. The This is due to the microstructure of concrete with nano-SiO2 is more uniform and compact than that of normal concrete and this yield to resist the water permeability [31].

\section{Chemical resistance}

Special liquid organic alkali-soluble incorporates with silicate additives increases the strength and the density of the silicate matrix. This interaction yields to prevent superficial pores, reduces shrinkage deformation and increases the resistance of aggressive media. Dangab et al. 2014 [32] investigated the effect of several produce of surface treatment. The kind of treatment divided in to three types of repellents (two water, three concrete sealers, two crack sealants). These produces keep longevity under traffic, the abrasion resistance, and effectiveness against salt scaling. The benefits of using these products for performance and reduction the mass loss of the concrete by $90 \%$ or more. The results recommended the crucial property in any good surface sealer of concrete achieved by high resistance to both gas and water penetration, crack sealant and water repellent applied to concrete.

\section{High performance adhesives}

In the expansion of new materials for construction, nanotechnology is extending to several other areas of property modifications. An extension to this technology could see structural adhesives using physical adhesion principles that would be more resistant to temperature than conventional adhesives used today.

\section{Discussion}

\section{Drawbacks of nanotechnology in repair and protection of reinforced concrete}

Europe standard for protection and repair of concrete structures (EN1504): It's difficult to understand and diagnose the deterioration of concrete. European norm is the first organization which set the principles for the repair and strength process. The new European norm EN 1504 will standardize repair activities and extend an improved frame for realizing successful, durable repairs, and, convinced customer. In $2008 \mathrm{EN} 1504$ presents the all sides of the repair process through: principals of repair, the accurate diagnosis of causes of defects before specification of the repair method, test methods, the control production of materials the quality control for the concrete manufacture.

Repair and prevention against damage caused by corrosion: Nano technology is considered to be solving damage the challenges of civil engineering. The recent development in nanotechnology is relevant to construction and studies the possibility benefits on the life and performance of civil engineering structures as bridges. Concrete repaired is a specialist activity requiring completely trained and respective personnel at all stages of the process. Nanotechnology can generate products with many amazing characteristics that can enhance the present construction materials: lighter and stronger structural composites, low maintenance coatings, better cementitious materials, lower thermal transfers rate of fire delaying and insulation, better sound absorption of sonic absorbers and better reflectivity of glass [33]. The utilize of nanomaterial in the composition of some materials, like cement, will conduct in significant lowering of $\mathrm{CO}_{2}$ pollution and the applying of performance thermal insulations will result in efficient use of energy for air conditioning. Olar [34] reported that nanomaterial can be applied to the surfaces of structural elements and this effect to environmental cleaning by photocatalytic reactions. Srivastava et. al. [35] clarified that nanotechnology made the concrete strong, durable and more easily placed. The steel is more toughness. The glass is selfcleaning. The paints are made more insulating and water repelling. Kalogeropoulou et al. investigated reinforcement corrosion protection through organic coatings and corrosion inhibitors under accelerated conditions and assesses physicochemical properties of these coatings, like liquid water permeability, water-vapor transmission rate and carbonation of concrete. In accelerated corrosion conditions the nanotechnology coating presents reduced protective ability. The corrosion inhibitor further improves the protection of reinforcement against corrosion in coated specimens, with the exception of the nanotechnology coating, which seems to perform poorly in aqueous environments [36]. Recently, nanotechnology has been playing substantial role for increasing and supporting innovative technological advances to manage the corrosion steel. Xianming [37] reviewed various applications related to the management of steel corrosion. He used nanotechnology to produce special type of steel. The steel has coatings to resist the abrasion and corrosion. This is yielded to improve the surface of steel designed for oxidizing and corrosive environments, and to make nano-sized additives for anti-corrosion coatings or intelligent corrosion protection systems, or for reducing the corrosion risk of the service environment. Falcóna et al. [38] study the effect of nanocontainers with dodecylamine encapsulated to protect the carbon steel from active corrosion. They used several polyelectrolytes and inhibitors were alternatively deposited on $\mathrm{SiO} 2$ nanoparticles surface for obtaining dodecylamine type. Yeh et al. were prepared a series of polymer-clay nanocomposite (PCN) materials by effectively dispersing the inorganic nanolayers of clay into an organic PSAN matrix by an in situ thermal polymerization. Organic styrene and acrylonitrile monomers were simultaneously into the interlayer regions of organophilic clay hosts and followed by a typical free-radical polymerization. All the PCN materials showed an increased Tg compared to that of pure PSAN depend on the DSC studies. This was temporarily referred to the confinement of the interaction polymer chains within the clay galleries, which blocks the segmental motions of the polymer chains [39]. The corrosion execution of ceramic membranes of SiO2-Al2O3 intended by the sol-gel dealing with organometallic compounds and deposited by dip-coating technique on 1008 steel foils has been investigated. G. 
Carbajal et al. (2001) presented the results gained by potential dynamic measurement techniques of sol-gel nanometer scale films of $\mathrm{SiO} 2$ $\mathrm{Al} 2 \mathrm{O} 3$ deposited onto a 1008 steel by dip-coating, achieved in watery solution $\left(0.5 \mathrm{M} \mathrm{H}_{2} \mathrm{SO}\right.$ and $\left.1 \mathrm{M} \mathrm{HCl}\right)$ at ambient temperature with energy dispersive spectroscopy (EDS) after testing. The tests showed that ceramic films manufactured from nanoparticles synthesized by sol-gel offer good corrosion protection in $\mathrm{H}_{2} \mathrm{SO}_{4}$ and $\mathrm{HCl}$ aqueous solutions at ambient temperature. Protection by the coatings was limited by the increasing of the membrane. The cracking of the film due to residual stress between the actual coating and the substrate. The corrosion on the substrate was increased by the formalization of iron oxides that had great influence on coating spalling around film cracks [40]. The protection of materials against environmental aggressive is related to adhesive and protective coatings. Several tests have been achieved on metals coated by $\mathrm{ZrO}_{2}, \mathrm{SiO}_{2}$ and $\mathrm{SiO}_{2}-\mathrm{TiO}_{2}$ to block corrosion and gas oxidation, hybrid coatings of $\mathrm{ZrO} 2-\mathrm{PMMA}$ and ceramic coatings of $\mathrm{Al}_{2} \mathrm{O}_{3}$ applied by plasma spraying [40].

Cathodic protection: A simple and effective method for the synthesis of nanoparticles is reported based on extreme cathodic polarization of a metal, formation of cation-stabilized metal anions, and their agglomeration. The development catalytic activity in the oxidation of carbon monoxide as well as methanol in the platinum. The chemical synthesis was developed by improving the metal nanoparticles which have been extremely active area of research for the last 30 years. This method depends on extreme cathodic polarization of a metal, leading to the structure of cation-stabilized metal anions, then formation of nanoparticles and considered a simple method of nanoparticles (Figure 9). The superior properties of nanoparticles relative to those of commercial catalysts were investigated. There is no efforts have been made to control either the size or preferential crystallographic orientation of the nanoparticles in the presence. However, it is possible to make some modification in the solution on the ac voltage, waveform, frequency, dc offset, temperature, stabilizing cation, metal pretreatment, concentration, and additives to predefined the features of synthesize nanoparticles. Lin et al. [41] demonstrated the way to assembly a uniformly on the surface of $\mathrm{TiO} 2$ nanotube arrays, a shellcore nanostructure $\mathrm{ZnS} / \mathrm{CdS}$ quantum dots (QDs). Sequence chemical bathed deposition (CBD) of CdS and $\mathrm{ZnS}$ in alcohol solution system was used. They characterized the chemical composition of thin films and the properties of morphology. They used the scanning electron microscopy, transmission electron microscopy and energy dispersive $\mathrm{X}$-ray spectroscopy to recognize the characteristic. It is clear that the nanostructured CdS QDs ( 20 cycles) coated on $\mathrm{TiO} 2$ nanotube arrays showed a remarkably enhanced photo electro chemical activity. Using ZnS QD shells (5 cycles) for coating is able to achieve the balance of the CdS under white-light irradiation. When the white light-irradiation turned off, the photo created cathodic protection of 403 stainless steels (403SS) can be stayed for several hours. Li et al. [42] and Xiutong et al. [43] studied photo electro chemical of CdS to modify $\mathrm{TiO} 2$ nanotube arrays. They tried to modify the photo anodes for cathodic protection of stainless steel. They reported that the nanoparticles modification of the electrodeposited $\mathrm{CdS}$ was highly-ordered $\mathrm{TiO} 2$ nanotube and its performance of photo cathodic protection. They demonstrated that the TNs incorporated by CdS effectively solar light in the ultraviolet visible (UV) furthermore the visible light (up to $480 \mathrm{~nm}$ ) region. It is supposed that the high photo electro-response activity of the CdSTNs is attributed to the increased efficiency of charge separation and transport of electrons. It is implied that the CdS-TNs are able to achieve a desired function a photo created cathodic protection for metals both under the UV and visible light illumination. Lattemannabc et. al. [44] studied the properties of carbon films deposited using mixed modes. In this method, the films consist of graphitic nanoclusters with a number density and morphology. These components depend on the bias utilized to the substrate. They reported the characterization thin films. They disposed at high rate and contain nanometer-sized graphitic clusters. The clusters are charged when embedded in the composite film depends on the applied substrate bias.

\section{Environment effects and safety of nanomaterials}

Nanotechnology can improve the service life by consideration the codes requirement for the concrete mix design; a long service life can be achieved by improving the quality of materials, reducing material degradation and minimizing penetration of gases and liquids that contribute to the damage of the material $[16,18]$. In the construction field, durable materials and a long service life are vital to reduce maintenance requirements and costs. Nanotechnology enhanced the service life for construction materials because the materials at the nano-scale specifically to reduce degradation. Where the nano-scale of materials improvements on the molecular structure. More researches were done in this field to discover the importance neural that has never before been possible to explore. Another mechanism was applied to as using barriers in the shape of surface anti-bacterial coatings [16]. Also using liquid and gasses can be selectively filtered by designing the coating as a molecular sieve, resisting specific sized materials which are watertight coatings that resist the penetration of the larger carbon dioxide molecule that is a known cause of carbonation in concrete [45]

\section{Conclusion}

1. Nanotechnology has amazed benefits in different applications in the construction industry.

2. The recent requirements in the construction industry will demonstrate great challenge to visualize the huge applications for the nanotechnology.

3. It is recommended to encouraging international industrial technology through joint ventures to achieve production and marketing in accordance with global quality standards.

4. Development of an effective means to ensure the quality of the distribution and spread of nano-materials in concrete mix is needed, which is essential for obtaining the required properties. It is becoming difficult with the addition of nanoparticles. The efficiency of the distribution relies on the type of high-addition additives for the mixing water used and the speed of rotation of the concrete mixer.

5. Providing a technological base specialized in nanotechnology is needed. It can be built from the human experiences in the Diaspora, taking into seeing the local characteristics of each industry in each country and working on the progression of human cadres through the programs of systems of expertise and technology in other developing countries, newly industrialized countries.

6. Nanotechnology has positive effect on the area of design, repair, protection, construction, maintenance.

7. It is substantial to launch the first code on the use Nanotechnology in construction

8. It is recommended to carefully studying the effect of nonmaterial on the heath of humans and the environment.

\section{References}

1. Khandve PV (2014) Nanotechnology for building material. Int J Sci: Basic Appl Res 4: 146-151.

2. BASF (2008) Nanotechnology for Simple, Successful Concrete Repair- A specifiers' guide. BASF company. pp. 1-24. 
3. Mansour NM, Zohre D (2006) Nanotechnology's role in optimization of energy consumption in buildings. $5^{\text {th }}$ Conference of Fuel Consumption Optimization of the Country.

4. Gogotsi Y (2006) Nanomaterials Handbook. Taylor \& Francis Group, LLC, USA.

5. Shaki BA, Houbi MV, Valinejadshoubi M (2014) Useable and precautionary aspects of using nanotechnology and nano- materials in the construction industry. Int $\mathrm{J}$ of Sci Engineer Technol Rese (IJSETR).

6. Pacheco-Torgal F, Jalali S (2011) Nanotechnology: Advantages and drawbacks in the field of construction and building materials. Constr Build Mater 25: 582 590.

7. Sanchez F, Sobolev K (2010) Nanotechnology in concrete- A review. Constr Build Mater 24: 2060-2071.

8. Ganesh VK (2011) Nanotechnology in Civil Engineering. Eur Sci J 8:27.

9. Li H, Xiao HG, Ou JP (2004) A study on mechanical and pressure-sensitive properties of cement mortar with nanophase materials. Cem Concr Res 34: 435-438.

10. Saurav (2012) Application of nanotechnology in building materials. Int $J$ Engineering Res Applications (IJERA) 2: 1077-1082.

11. Pattanaik SC (2011) Self-sealing crystalline coating and self-cleaning nanocoating for the concrete substrate for a sustainable development. Conference Proceedings of International Conference (ICTACE), Hyderabad.

12. Patel AS (2013) An Overview on application of nanotechnology in construction industry. IJIRSET 2: 6094-6098.

13. Mann S (2006) Nanotechnology and construction. European nanotechnology gateway - Nanoforum Report, Institute of Nanotechnology 2-10.

14. American Concrete Institute (2017) Report on application of nanotechnology and nanomaterials in Concrete. ACl Committees 236 and 241.

15. Sobolev K, Gutiérrez MF (2005) How nanotechnology can change the concrete world. American Ceramic Society Bulletin 84: 14

16. Ake S (2009) RILEM TC-NCM: Draft Chapter in TC Report. Version 060509 , BIC-Swedish Construction Sector Innovation Centre. 48.

17. Ken PC, Edward JG (2002) Smart and designer structural material systems. Progress in structural Engineering and Materials 4: 417-430.

18. NANOCONEX final technical report: Towards the setting up of a network of excellence on nanotechnology in construction. (2004) Fundacio'n LABEIN, Labein Centro Technologico.

19. RPI (Rensselaer Polytechnic Institute) (2007) Using nanotubes to detect and repair cracks in aircraft wings, Other Structures.

20. Kuennen T (2004) Small science will bring big changes to roads. Better Roads, IL, USA.

21. Florence S (2005) Prestigious Award for Nano-Fiber Reinforced Concrete. Vanderbilt University, USA.

22. Wegner TH, Winandy JE, Ritter MA (2005) Nanotechnology opportunities in residential and non-residential construction. 2nd International Symposium on Nanotechnology in Construction, Bilbao, Spain.

23. Mulenga DM (2009) Can nanotechnology address today's civil engineering challenges? Structures Congress.

24. Alsaffar KA (2014) Review of the use of nanotechnology in construction industry. IJERD 10: 67-70.

25. Qing Y, Zenan Z, Li S, Rongshen C (2006) A comparative study on the pozzolanic activity between nano-SiO2 and silica fume. J Wuhan Univ Technol Mat Sci Edit 21: 153-157.
26. Li H, Zhang MH, Ou JP (2007) Flexural fatigue performance of concrete containing nano-particles for pavement. Int J Fatig 29: 1292-1301.

27. Kuo WY, Huang JS, Lin CH (2006) Effects of organo-modified montmorillonite on strengths and permeability of cement mortars. Cem Concr Res 36: 886-895.

28. Sobolev K, Flores I, Hermosillo R, Torres-martínez LM (2006) Nanomaterials and nanotechnology for high performance cement composites" Proceedings of $\mathrm{ACl}$ Session on Nanotechnology of Concrete: Recent Developments and Future Perspectives.

29. Peng B, Locascio M, Zapol P, Li S, Mielke S, et al. (2008) Measurements of near-ultimate strength for multiwalled carbon nanotubes and irradiationinduced crosslinking improvements. Nat Nanotechnol 3: 626-631.

30. Sasmal S (2013) Can carbon nanotubes make wonders in civil/structura engineering? Progress in Nanotechnology and Nanomaterial 2: 117-129.

31. Ardalana RB, Jamshidib N, Arabameric H, Joshaghanid A, Mehrinejade M, et al. (2017) Enhancing the permeability and abrasion resistance of concrete using colloidal nano-SiO2 oxide and spraying nanosilicon practices. Constr Build Mater 146: 128-135.

32. Danga Y, Xie N, Kessel A, McVey E, Pace A, et al (2014) Accelerated laboratory evaluation of surface treatments for protecting concrete bridge decks from salt scaling. Constr Build Mater 55: 128-135.

33. Lee J, Mahendra S, Alvarez PJJ (2010) Nanomaterials in the Construction Industry: A Review of their Applications and Environmental Health and Safety Considerations. ACS Nano 4: 3580-3590.

34. Olar R (2011) Nanomaterials and Nanotechnology for Civil Engineering Buletinul Institutului Politehnic Din laşi 4: 110-117.

35. Srivastava A, Singh K (2011) Nanotechnology in civil engineering and construction: A review on state of the art and future. In: Proceedings of Indian Geotechnical Conference 1077-1080.

36. Kalogeropoulou S, Pantazopoulou P (2015) Study of corrosion protection offered to concrete reinforcement by organic coatings and inhibitors. A -Technology and Sciences 15: 31-40.

37. Xianming S (2010) On the use of nanotechnology to manage steel corrosion Recent Patents on Engineering 4: 44-50.

38. Falcóna JM, Batistab FF, Aoki IV (2014) Encapsulation of dodecylamine corrosion inhibitor on silica nanoparticles. Electrochim Acta 124: 109-118.

39. Yeh JM, Liou SJ, Lu HJ, Huang HY (2004) Enhancement of corrosion protection effect of poly (styrene-co-acrylonitrile) by the incorporation of nanolayers of montmorillonite clay into copolymer matrix. J Appl Polym Sci 92: 2269-2277.

40. Carbajal G, Martínez $\square$ Villafañe A, Gonzalez-Rodriguez JG, Castaño VM (2001) Corrosion-resistant coatings: A nanotechnology approach. Anti-Corrosion Methods and Materials 48: 241-244.

41. Lin ZeQ, Lai YK, Hu RG, Li J, Du RG, et al. (2010) A highly efficient ZnS/ CdS@TiO2 photoelectrode for photogenerated cathodic protection of metals. Electrochim Acta 55: 8717-8723.

42. Li J, Lin CJ, Li JT, Lin ZQ (2011) A photo-electrochemical study of CDS modified $\mathrm{TiO} 2$ nanotube arrays as photoanodes for cathodic protection of stainless steel. Thin Solid Films 519: 5494-5502.

43. Li H, Wang X, Zhang L, Hou B (2015) Preparation and photocathodic protection performance of $\mathrm{CdSe} /$ reduced graphene oxide/TiO2 composite. Corros Sci 94 342-349.

44. Lattemannabc M, Abendrothd B, Moafie A, McCulloche DG, McKenziea DR (2011) Controlled glow to arc transition in sputtering for high rate deposition of carbon films. Diam Relat Mater 20: 68-74.

45. Mobasser SH, Firoozi AA (2016) Review of Nanotechnology Applications in Science and Engineering. J Civil Eng Urban 6: 84-93. 